\title{
Expresión de Puerto Rico en la literatura contemporánea *
}

$(1934$ - 1956)

$\mathbf{P}$ UERTO RICO pasó los primeros lustros de esta centuria en busca de su expresión, vacilante en medio de su destino entre el pasado de raíces insulares hispánicas y el presente lleno de perplejidades en relación con los Estados Unidos. El desasosiego cultural provocado por el traslado histórico de la isla se reveló esencialmente en el aspecto lingüístico. Desde los albores del siglo veinte surgió la voz de alarma de José de Diego (1867-1918), en pro de la lengua castellana, baluarte de la nacionalidad puertorriqueña. Del 1927 al 1928 Navarro Tomás confirmó con sus investigaciones sobre El Español en Puerto Ríco (1948), "la propiedad con que los elementos más decisivos en el funcionamiento orgánico del idioma desempeñan su papel hasta en los rincones más escondidos de la isla". Años más tarde, Pedro Salinas deja como secuela de su estancia en Puerto Rico el famoso discurso del 1944, Aprecio y Defensa del Lenguaje, inspirado por esta dimensión entrañable del ser o no ser de nuestro pueblo, junto a los hermosos poemas al mar de San Juan, El Contemplado.

El afán de hacer a Puerto Rico un país bilingüe durante más de medio siglo no ha podido vencer la hegemonía del español, el único lenguaje que Puerto Rico reconoce como suyo.

* Trabajo leído en la Convención Anual de la "Modern Language Association, en Washingtón, en diciembre de 1956. 
No podría cantarse esta victoria, sin embargo, sin el apoyo vital del pueblo que ha conservado y enriquecido su herencia lingüística con un tesón inalterable y ejemplar. El habla del jíbaro, el folklore musical y poético vinculado a sus costumbres y fiestas tradicionales, son la cantera inexhausta en la cual el escritor culto halla un filón de inspiración y de esperanza. De esas raíces hereditarias se nutre la literatura contemporánea de la isla.

Las fuentes cultas de esta etapa están ligadas a la generación del 98 en el lenguaje y las predilecciones de los prosistas, cuya filiación afectiva con las ideas y el estilo de Azorín, Ortega y Unamuno, es motivo de orgullo y de prestigio. Los poetas tienden a acogerse a la sombra de Juan Ramón Jiménez, de García Lorca, de los místicos del Siglo de Oro, además de frecuentar el trato de la lírica inglesa y francesa. Del clima hispanoamericano se captan las huellas de los artistas y pensadores desde Rodó y Darío hasta Alfonso Reyes y Gabriela Mistral. No obstante, la herencia de lo puertorriqueño mismo es menos perceptible. Por circunstancias complejas de la historia, se había desterrado a Puerto Rico de la escuela desde el 1898 hasta muy recientemente: El Gíbaro de Manuel Alonso (1822-1889), al igual que el poeta gongorino Ayerra y Santa María (1630-1708), y el náufrago Alonso Ramírez (16621700), inmortalizado por Siguienza y Góngora, permanecían relegados al olvido, ignorándose que eran compatriotas lejanos del siglo XVII, distinguidos en las letras de la Nueva España. Durante la jornada posterior a la Primera Guerra Mundial hasta el 1932 más o menos los escritores del presente estaban en la niñez y la adolescencia. Despertaban a la literatura leyendo las obras de los clásicos y modernos de España y de Francia, no tanto las de los hispanoamericanos, y los más curiosos buscaban las obras de los escritores ingleses, norteamericanos, rusos, escandinavos, etc... todo lo que se leía entonces en las esferas intelectuales del mundo. Los jóvenes de las generaciones nuevas leen hoy con igual avidez a Sartre, a Kafka, a Rilke, a Faulkner.

De todo lo expuesto se deduce una sencilla verdad: al escritor contemporáneo de Puerto Rico le atrae la cultura occidental lo mismo que la insular, pero siente la necesidad y la 
urgencia de volver a las corrientes propias, y de conocerse mejor para aprovechar mejor las corrientes extranjeras. Darle valor a lo autóctono es el impulso mayor en la literatura desde el 1934 hasta el presente. Los escritores de estos años han salvado con devoción y estudio lo que se les negó en la infancia y la primera juventud: el conocimiento y el respeto de su pasado histórico y cultural. La literatura erudita ha adquirido dimensiones importantes: los ensayos y las monografías más significativas, con muy pocas excepciones, se inspiran en el folklore, la historia y la literatura desconocida de la isla.

En las obras fundamentales correspondientes a los años del 1934 al 1956 se puede apreciar el perfil diferenciador de Puerto Rico en el mapa cultural hispánico. La importancia de la isla en el conjunto americano debe ser motivo de reflexión futura. De ningún modo pretendemos enjuiciar su valor en este breve espacio. A grandes rasgos sí podemos trazar un bosquejo esquemático de la trayectoria del escritor puertorriqueño. Antonio S. Pedreira (1899-1939), maestro de mi generación, publica Insularismo en 1934, obra de introspección y búsqueda de lo puertorriqueño, la cual desata una corriente fecunda de estudio y de creación inspirada en los temas de la tierra. Ya en 1932 Pedreira había publicado una magnífica $B i$ bliografía, fuente indispensable de información para todo el que estudie la cultura de Puerto Rico. Tomás Blanco sigue a Pedreira con el Prontuario Histórico, en el cual reseña la evolución del país desde la época pre-colombina hasta el 1935. A partir de entonces se multiplican las obras de carácter valorativo y analítico de los componentes culturales integrados en la realidad puertorriqueña.

Tanto en el ensayo como en el teatro y en la literatura narrativa se advierte el despertar de la conciencia creadora para ver y sentir lo que se tiene al alcance de la mano y el corazón, inseparablemente de las inquietudes estéticas y filosóficas de proyecciones universales. La crítica de autores y de obras nacionales y extranjeras, además de la obra puramente imaginativa, ha adquirido paralelamente un auge $y$ un cultivo sin precedentes. Escritores como Tomás Blanco, Hernández Aquino, Enrique Laguerre, Manrique Cabrera, Fernández Méndez, José A. Balseiro, José Emilio González, y varios más 
cuyo nombre se escapa involuntariamente, han dedicado tiempo y espacio al cultivo de la obra propia, de expresión puramente creadora, al igual que al trabajo erudito de crítica y de investigación. El año 1955 es significativo: Josefina Rivera de Álvarez publica un buen Diccionario de Literatura Puertorriqueña, y Francisco Manrique Cabrera escribe el primer manual de la historia literaria nacional. Asomante, la mejor revista del país, y una de las mejores de América, celebra los diez primeros años de su existencia dedicando los dos números iniciales del año a las letras contemporáneas de Puerto Rico. Si repasamos la bibliografía de la etapa que nos ocupa hallamos valiosos libros de estudio escritos por Concha Meléndez, Margot Arce, Nilita Vientós, José Balseiro y Domingo Marrero.

La novela de Enrique Laguerre se conoce desde el 1935. En La llamarada, su obra más importante, se incorpora el cañaveral a las llanuras, las selvas y las pampas de la novelística hispanoamericana. El cuento puertorriqueño irrumpe cada vez con más fuerza y personalidad en la escena narrativa. Después de Miguel Meléndez Muñoz y Emilio S. Belaval, el cuentista joven que más se ha destacado es Abelardo Díaz Alfaro, autor de Terrazo (1947). Las obras teatrales han ganado en perspectiva. Entre sus mejores cultivadores se debe mencionar a Francisco Arriví junto a René Marqués, autor de $L a$ carreta (1952). Estimo La carreta de Marqués una de las comedias mejor logradas de la literatura teatral contemporánea en lengua española. El juicio del distinguido mexicano Ermilo Abreu Gómez coincide con el mío al afirmar que " $L a$ carreta, por su estructura y por su tema, es una de las obras maestras del teatro hispanoamericano".

La poesía lírica es la expresión más íntima y elocuente de las aspiraciones creadoras del escritor puertorriqueño. Después de Luis Lloréns Torres (1876-1944), el poeta nacional de la tierra, contemporáneo de Virgilio Dávila (1869-1943), cantor criollo del pueblo y del campo, la lírica postmodernista ha seguido un rumbo vertical, perdiendo en horizontes exteriores lo que ha ganado en subjetivismo. Muchos buenos poetas vanguardistas de Puerto Rico han dado genuinas muestras de originalidad. Evaristo Ribera Chévremont y Luis Palés Matos 
quiżás representen la cumbre en el devenir de la lírica ya consagrada. Entre los más jóvenes merecen destacarse entre los mejores poetas del presente a Luis Hernández Aquino, Juan Antonio Corretger, Julia de Burgos (1914-1953), Francisco Manrique Cabrera, Clara Lair y Francisco Matos Paoli.

Podría decirse a manera de síntesis que el cuento, la novela y el ensayo se han dedicado desde el 1934 al esclarecimiento de los valores nacionales y al examen de las ideas, incluyendo en su repertorio interesantes incursiones por el mundo poético y filosófico de grandes escritores de afuera: Ortega y Gasset, García Lorca, Henry James, Alfonso Reyes, Unamuno, Azorín, etc., han servido de tema a algunas de las obras más interesantes y valiosas de la crítica puertorriqueña y constituyen una contribución de mérito al conocimiento de estos autores. La poesía, mientras tanto, se caracteriza por una inquietud trascendente, se desprende de los afanes del vivir cotidiano y desplaza la sencillez y la "difícil facilidad" de su entraña boricua hacia nuevas aventuras metafóricas, pero sin perder el contacto con la experiencia vital de su pueblo.

En conclusión: la literatura contemporánea de Puerto Rico expresa el dramatismo de la vida puertorriqueña en el siglo Xx: la pugna por no dejar morir ni su lengua, ni sus tradiciones, ni sus preciadas cualidades de pueblo antillano. Siendo nuestra isla la única tierra del Caribe vinculada políticamente a los Estados Unidos desde el 1898 es de suma importancia y de proporciones heroicas el esfuerzo de los puertorriqueños por sobrevivir dentro de esa relación con una cultura extranjera, afirmando en la obra literaria su identificación con el mundo de lengua española. Con un sentimiento fraternal y espontáneo, Mariano Picón Salas le dedicó a Puerto Rico hace precisamente diez años -1946-, una de las arengas más hermosas que ha provocado nuestra tierra. La titulo Apología de la Pequeña Nación, y en ella manifestaba que "Puerto Rico tiene que hablar a la América entera". Añadía algo más: "Puerto Rico está en el cruce e intimidad de más de veinte naciones que desean escucharlo". Creo que nuestros escritores han recogido el mensaje del amigo venezolano y han respondido a la llamada. La pequeña nación del Caribe se ha hecho 
eco de la voz de Picón Salas. En la poesía y en la prosa de la última década sobre todo ha retoñado el eterno romanticismo boricua con un matiz austero y elegante; se han salvado la tradición hispánica y el criollismo; y Puerto Rico ha afirmado su personalidad en las letras. Un magnífico haber de obras coloca hoy a la literatura de la isla entre las más vigorosas del conjunto hispanoamericano. El tema nacional, el lenguaje y el estilo, el timbre isleño, la voz autóctona de nuestro boricuismo, distinguen de la española y de la hispanoamericana a la literatura de Puerto Rico en el siglo Xx.

La expresión de la isla reclama, pues, la atención de los lectores y los investigadores de las letras hispanoamericanas.

María Teresa Babín, New York University, New York 3, New York 